\title{
AN INVESTIGATION INTO EFL TEACHERS' PERCEPTIONS OF IN-CLASS ENGLISH SPEAKING ASSESSMENT
}

\author{
Nguyen Ho Hoang Thuy ${ }^{1, *}$, Tran Thi Thanh $\mathrm{Nga}^{2}$ \\ ${ }^{1}$ University of Foreign Languages, Hue University, \\ 57 Nguyen Khoa Chiem, An Cuu, Hue, Vietnam \\ ${ }^{2}$ Huong Hoa Upper-secondary School, Huong Hoa, Quang Tri, Vietnam
}

Received 25 January 2018

Revised 11 March 2018; Accepted 30 March 2018

\begin{abstract}
The study was conducted to explore EFL teachers' perceptions of in-class English speaking assessment. The constructs of teachers' perceptions investigated in the current research included their general understanding of speaking assessment, the task types of in-class speaking assessment, and the teachers' work involved in the assessment implementation. Questionnaire and interview were employed as data collection instruments of the study. Forty-two EFL teachers at different high schools in Quang Tri, Vietnam responded to the questionnaire and then five of them participated in the subsequent interview sessions. The findings revealed that the teachers' perceptions of in-class English speaking assessment in terms of three investigated aspects were generally appropriate. Nonetheless, the teachers showed their limited knowledge about oral portfolios as a speaking assessment type; they also articulated their need for more instruction on how to implement self-assessment as a type of English speaking assessment.
\end{abstract}

Keywords: teachers' perceptions, speaking assessment, assessment task type

\section{Introduction}

Along with the implementation of the English pilot program, it is required by the Vietnam Ministry of Education and Training (MOET) that English testing and assessment be comprehensively conducted in terms of four skills, namely reading, writing, speaking and listening (Dispatch No 5333/ BGDĐT-GDTrH) so that students, upon their completion of high school education, will have achieved level three of the Foreign Language Proficiency Framework for Vietnam, which is equivalent to B1 level in the Common European Framework of Reference for Language (CEFR). In the light of MOET document, high school students should be able to communicate in English in both spoken and written forms. Nonetheless, English speaking assessment has not been the

${ }^{*}$ Corresponding author: Tel.: 84-914479247

Email: nhhthuy@hueuni.edu.vn main focus of language assessment at high school, both in one-period tests and end-ofsemester tests; it has yet been administered in any formal examinations either, including the national high school graduation examination. Research has been conducted on the difficulties in implementing in-class English speaking assessment and the required resources for its effective practice (e.g., Tran \& Nguyen, 2017). How EFL teachers perceive and practice English speaking assessment at high schools in Vietnam remains little known. The current research therefore took an initial step by exploring EFL teachers' perceptions of in-class English speaking assessment in terms of their general understanding, the task types of in-class speaking assessment and the teacher's work involved in the assessment implementation at some high schools in Vietnam. 


\section{Literature review}

Language assessment is defined as an ongoing process of judgment, encompassing a teacher's comments and written phrases responding to students' language performance as well as a form of reporting measurement (Brown, 2004; To, 2010). Brown also claimed that language assessment can be categorized in terms of intention (informal or formal) and purpose (formative or summative). Informal assessment involves any kind of incidental, unplanned comments and responses, along with coaching and other impromptu feedback to the student's work such as "nice job", "good work", etc. Teacher's informal assessment carried in classroom tasks aims to elicit students' performance, not to make final results or judge students' competence. On the other hand, formal assessment deals with the planned techniques and systematic methods used by the teacher in order to get into students' achievement. Assessment is called assessment for learning or formative assessment when it is intended to give feedback to learners during a course, whereas assessment is called assessment of learning or summative assessment when it is used at the end of a term, a semester or a year to measure students' learning (Brown, 2004; Hattie \& Timperley, 2007).

English speaking assessment, however, has been considered difficult and challenging (Kim, 2003; Luoma, 2004; Chuang, 2007; Waugh \& Joliffe, 2008). Speaking assessment is troublesome because only a few minutes' speaking evidence is not sufficient to judge a learner's competence (Waugh \& Joliffe, 2008). Moreover, the assessment of oral production is challenging due to the nature of speaking itself. Luoma (2004) argued that it is especially challenging to assess speaking because of the many different factors that influence the way teachers evaluate oral proficiency. Elements that are considered typically important include accent, grammar, vocabulary, errors and the ability to use language appropriately for the purpose of speaking. Sharing this viewpoint, other researchers, for example, Madsen (1983), Taylor (2006), Chuang (2007), and Winke, Gass and Myford (2011), stated that speaking assessment is challenging because there are many external and internal factors that influence instructors' impression on how well someone can speak a language and these may be reflected in the assessing or scoring of learners' speaking. Since it is not easy to define the components of speaking ability clearly, the identification of the components to be assessed in a speaking test causes another difficulty (Madsen, 1983). In addition, even when test designers attempt to develop a detailed scoring rubric and conduct intensive rater training (Winke et al., 2011), the reliability of scoring has permanently been doubted since speaking assessment requires instructors' personal subjective views instead of their purely objective points of view (Chuang, 2007).

The challenging nature of English speaking assessment has inspired a growing body of research in the field. These studies focused particularly on investigating the perceptions and practice of English speaking assessment. Researchers have attempted to explore the practice of in-class English speaking assessment in different contexts, for example, ranging from Asian context like schools in Korean (e.g., Kim, 2003; Lee, 2010) to European context like schools in Norway (e.g., Agasøster, 2015). Different aspects of teacher's beliefs in the orientation and purpose of assessment practices, teachers' role in oral language assessment, and the effectiveness of classroom speaking assessment were also examined (e.g., Chang, 2006; Lee, 2010). 
In addition, some other researchers were interested in investigating both the teachers' perceptions and beliefs about speaking assessment and the mismatch between these perceptions and beliefs and their assessment practice in class (e.g., Muñoz et al., 2003; Fetene, 2008; Bingqing, 2009; Grada, 2014). In the context of Vietnam, this research area has also been explored though on a relatively smaller scale (e.g., Tran, 2010; Truong, 2010; Nguyen, 2013; Tran \& Nguyen, 2017).

The aforementioned studies provide insights into EFL teachers' perceptions and practice of speaking assessment in the classroom. Concerning research on teachers' perceptions, it can be said that although the number of studies on teachers' perceptions on EFL assessment is massive, that on EFL speaking assessment is still limited. Moreover, such studies on teachers' perceptions on EFL speaking assessment concentrate primarily on assessment necessity, assessment effectiveness and assessment criteria. Consequently, the current study was conducted to investigate EFL teachers' perception on in-class speaking assessment, focusing not only on the teachers' understanding of speaking assessment but also the task types of in-class speaking assessment, and the teachers' work involved in the assessment implementation.

\section{Research methodology}

\subsection{Participants}

The current study involved forty-two EFL teachers, 38 females and 4 males with their age ranging from 23 to 50 , as research participants. These teachers came from 15 different high schools in Quang Tri province with their English teaching experience being from 1 to 22 years. Five out of 42 participants got MA degree and the rest (37) BA.
The number of 15 high schools accounts for almost $50 \%$ of the total high schools in Quang Tri province. Moreover, the number of 42 participants involved in the study accounts for approximately $22 \%$ of the population of English high school teachers in Quang Tri province. According to Dörnyei (2003), the minimum of sample number should be between 1-10\% of the population. However, McMillan and Schumacher (1993) suggested that the largest sample possible should be used since the larger the sample the more representative it will be of the population. Therefore, 42 participants from 15 high schools were expected to provide sufficient information to guarantee the data reliability.

Since the research framework for exploratory studies like the current study has not been well established, the design of data collection instruments as well as the methods for data analysis and interpretation as presented below were primarily based on the synthesis of the findings from the available studies.

\subsection{Data collection}

Questionnaires and in-depth interviews were employed in this study to explore the EFL teachers' perceptions on in-class speaking assessment.

A questionnaire was designed with 44 question items being divided into three categories: General understanding of speaking assessment (items 1-10); Task types of in-class speaking assessment (items 11-21) and Teachers' work involved in assessment application process (items 22-44). All of these items were presented following the 5-point Likert scale ranging from strongly disagree (1), disagree (2), undecided (3), agree (4) and strongly agree (5). In the first category General understanding of speaking assessment, the 10 items which elicit information about teachers' perception on the necessity and 
reasons or purposes for in-class speaking assessment were adapted from Kim's (2003), Munoz et al's (2003) and Lee's (2010) studies. In the second category Task types of in-class speaking assessment, Kim's (2003) and Munoz et al's (2003) studies provide the basis to develop the 11 items in order to obtain teachers' perception of tasks and activities which can be used in in-class speaking assessment. The last category Teachers' work involved in assessment application process contains 24 items which were related to the work teachers do in assessment process. The teachers' job was separated into three stages namely pre-, while- and post-, which respectively means the work teachers prepare for assessment, the work teachers do while conducting assessment and the work teachers do after completing assessment activities. The question items for the pre-stage and the while-stage were mainly synthesized from Grada's (2014) study while the items for the post stage were adapted from Fetene's (2008) study.

The participants were asked to decide if they wished to receive the questionnaire via email or face-to-face. The questionnaires were then delivered to 60 teachers, 20 faceto-face and 40 online. 42 questionnaires were returned afterwards, among which 24 were obtained from online contacts. After the questionnaire data was analyzed, 5 teachers were selected to participate in the interviews for more clarification.

Interview was selected as a supplementary data collection instrument in the current study; therefore, the interview questions were designed after the data from questionnaires were collected and analyzed. Data in the interviews were expected to provide further information and more clarification for some issues emerging from the questionnaires. Specifically, the interview consisted of 7 questions related to the questionnaire items of which the mean and standard deviation indicate much difference from the other items in the questionnaire.

\subsection{Data analysis methods}

All data from the questionnaire were analyzed and interpreted using descriptive statistics. Specifically, basing on the low value 1 and the high value 5 of the Likert scale, the teachers' perceptions of in-class speaking assessment were categorized into three levels: high, medium and low. The formula to calculate the interval scale was $(\operatorname{Max}-\mathrm{Min}) / \mathrm{n}=(5-1) / 3=1.33$. Therefore, the low level was 2.33 calculated by the low value plus $1.33(1+1.33=2.33)$; the medium level was $3.66(2.33+1.33=3.66)$; and the high level was $5(3.66+1.33=5)$ (adapted from Pham \& Tran's study, 2014). After all, the range of mean from 1 to 5 was categorized into 3 levels: low value mean from 1-2.33; medium value mean from 2.34-3.66; and high value mean from 3.675.0. The data of this part were presented in tables and charts with the mean score and standard deviation.

The interview recordings were first transcribed, then categorized, synthesized and analyzed using thematic analysis. The analyses were used for the purpose of supporting, clarifying and providing further information for the questionnaire findings.

\section{Findings and discussion}

\subsection{Teachers' general understanding of speaking assessment}

The questionnaire data about teachers' general understanding of speaking assessment were analyzed and summarized in Table 1. It is obvious that the participants have positive perceptions in terms of their general understanding of in-class speaking assessment with the total mean value being 4.17, which is within the range of high level, from 3.67-5.0. 
Table 1. Teachers' perception of in-class speaking assessment - their general understanding

\begin{tabular}{|c|c|c|c|c|}
\hline No & Items & $\mathbf{N}$ & $\mathbf{M}$ & S.D \\
\hline 1 & Speaking assessment is very necessary for teachers. & 42 & 4.55 & 0.59 \\
\hline 2 & Speaking assessment is very necessary for students. & 42 & 4.64 & 0.53 \\
\hline 3 & $\begin{array}{l}\text { Teachers should specify the purpose of assessment when they assess } \\
\text { students' language performance. }\end{array}$ & 42 & 4.45 & 0.59 \\
\hline 4 & $\begin{array}{l}\text { In-class speaking assessment is conducted to give students grade which } \\
\text { informs them of their own development. }\end{array}$ & 42 & 3.83 & 0.76 \\
\hline 5 & $\begin{array}{l}\text { In-class speaking assessment is conducted to give students feedback on their } \\
\text { own progress. }\end{array}$ & 42 & 4.36 & 0.79 \\
\hline 6 & $\begin{array}{l}\text { In-class speaking assessment is conducted to inform teachers of students' } \\
\text { progress. }\end{array}$ & 42 & 4.05 & 0.91 \\
\hline 7 & $\begin{array}{l}\text { In-class speaking assessment is conducted to set further learning objectives } \\
\text { for teachers. }\end{array}$ & 42 & 3.93 & 0.78 \\
\hline 8 & $\begin{array}{l}\text { In-class speaking assessment is conducted to diagnose the students' strengths } \\
\text { and weaknesses. }\end{array}$ & 42 & 4.24 & 0.66 \\
\hline 9 & $\begin{array}{l}\text { In-class speaking assessment is conducted to indicate the students' levels of } \\
\text { speaking proficiency. }\end{array}$ & 42 & 4.05 & 0.88 \\
\hline 10 & $\begin{array}{c}\text { In-class speaking assessment is conducted to indicate the students' } \\
\text { achievement of a semester. }\end{array}$ & 42 & 3.60 & 1.01 \\
\hline \multicolumn{2}{|r|}{ Total Mean } & & 4.17 & \\
\hline
\end{tabular}

Among the 10 items, items 1 and 2 which refer to the necessity of assessment receive the highest mean scores of 4.55 and 4.64 , respectively. This result is relevant to Kim's (2003) study, in which almost all the participants also had positive attitudes toward the necessity of speaking assessment.

Regarding the purposes of speaking assessment in classroom, there is a slight variation from item 3 to item 10. Specifically, item 3 reaches the highest mean value (4.45) which implies that most teachers think they should set clear purposes for assessment. In contrast, item 10 gets the lowest mean value (3.60) being in the range of medium level. In comparison with the formative purposes of in-class speaking assessment (items 4-9) at the high level, the summative purpose (item 10 ) is much lower, at the medium level. In addition, item $5(\mathrm{M}=4.36)$ gets a higher mean score than item $4(\mathrm{M}=3.83)$, which means that within the two purposes of speaking assessment, namely giving grade and giving feedback, the participants prefers the second one.

It can be inferred that the teachers have appropriate perceptions of the purposes for inclass speaking assessment and they are in favor of the purposes of formative assessment rather than of summative assessment. Kim's (2003) and Lee's (2010) studies showed different results whereby classroom speaking assessment were conducted mainly because of the compulsory requirements. Lee (2010) claimed that the main purposes of classroom speaking assessment are to evaluate a unit of work and to follow requirements of the educational policy. Administrative and social 
requirements were also reflected as speaking assessment purposes in Kim's (2003) study. The Vietnamese current context is not such a case when speaking assessment has not been officially required for the high school program by the Ministry of Education Training. This
4.2. Teachers' perception of the task types of in-class speaking assessment

The teachers' perception of the task types employed in classroom speaking assessment was analyzed and summarized in Table 2.

Table 2. Teachers' perception of task types of in-class speaking assessment

\begin{tabular}{|c|c|c|c|c|}
\hline No & Items & N & M & S.D \\
\hline 11 & Teachers can use presentation as a task type for speaking assessment. & 42 & 4.10 & 0.91 \\
\hline 12 & Teachers can use role-play as a task type for speaking assessment. & 42 & 4.43 & 0.50 \\
\hline 13 & Teachers can use informal conversation as a task type for speaking assessment. & 42 & 4.17 & 0.62 \\
\hline 14 & Teachers can use picture description as a task type for speaking assessment. & 42 & 4.38 & 0.54 \\
\hline 15 & Teachers can use portfolios as a task type for speaking assessment. & 42 & 3.26 & 1.11 \\
\hline 16 & Teachers can use games as a task type for speaking assessment. & 42 & 3.45 & 1.09 \\
\hline 17 & Teachers can use question and answer as a task type for speaking assessment. & 42 & 3.95 & 0.79 \\
\hline 18 & Teachers can use interviews as a task type for speaking assessment. & 42 & 4.52 & 0.55 \\
\hline 19 & $\begin{array}{c}\text { Teachers can use information gap activities as a task type for speaking } \\
\text { assessment. }\end{array}$ & 42 & 3.64 & 1.23 \\
\hline 20 & Teachers can use student self-assessment as a task type for speaking & 42 & 3.40 & 0.99 \\
\hline 21 & Teassessment. & 42 & 3.81 & 0.59 \\
\hline & Total Mean can use peer assessment as a task type for speaking assessment. & $\mathbf{3 . 9 2}$ & \\
\hline
\end{tabular}

may be one of the main reasons why the participants in this study leaned to the formative purposes. One teacher asserted by saying: "in class speaking assessment should be conducted not only to indicate the students' achievement of a semester, but also to help students improve their speaking skills. It also helps teachers adjust their teaching methods."

In short, teachers' general understanding of in-class speaking assessment with regard to the necessity and the purposes of speaking assessment are highly positive. They not only realize the necessity of assessment but also prefer the formative purposes to the summative ones.
As can be seen from Table 2, the participants have positive perceptions of different task types of in-class speaking assessment with the total mean value 3.92. Seven out of 11 task types are ranged at the high level including presentation, role-plays, informal conversation, picture description, question and answer, interviews and peer assessment. The 4 other types: portfolios, games, information gap activities and selfassessment are at the medium level. The order from the largest to the smallest mean value according to the participants' selection is displayed in Figure 1. 


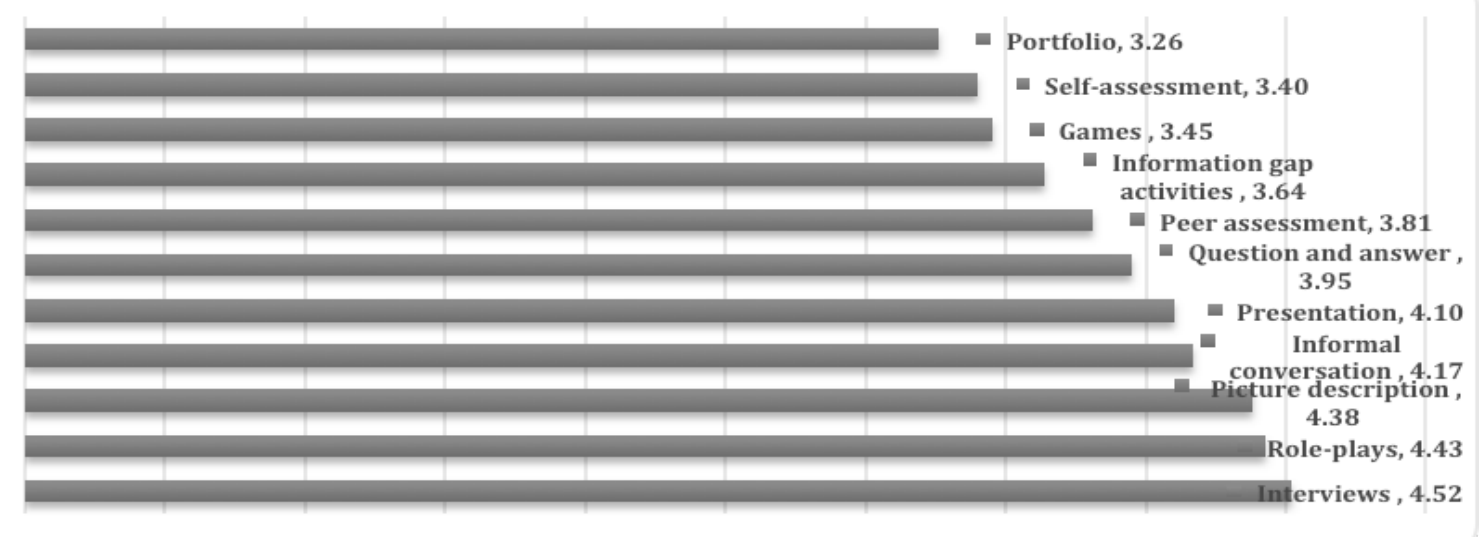

Figure 1. The order of task types of in-class speaking assessment

In Figure 1, interviews and role-plays are favored as task types used for in-class speaking assessment by all participants with the very high mean values being 4.52 and 4.43 , respectively. It is also noticeable that interviews and role-plays involve very high interaction between teachers and students and/or between students and students. On the contrary, the task types that obtained the lowest mean values include portfolios $(\mathrm{M}=3.26)$ and self-assessment $(\mathrm{M}=3.40)$.

The findings from Table 2 and Figure 1 indicate both similarities and differences when comparison was made with previous studies.

The first similarity is that the participants in Kim's (2003), Munoz et al's (2003), Bingqing's (2009), and Lee's (2010) studies considered role-plays as the most frequently used task. Information gap activities were also not preferred in Kim's (2003) and Bingqing's (2009) studies; moreover, self-assessment was considered as an inappropriate tool of speaking assessment in Grada's (2014) study. The interviewees in Grada's (2014) study admitted that they lacked knowledge of student self-assessment and did not have experiences of using it. One of the teachers in the current study, despite having experienced utilizing self-assessment, still underestimated this task type for speaking assessment by stating that "from my experience, students are not really serious in assessing themselves, so I will not use self-assessment for assessing speaking". Finally, the teachers stated that portfolio is not suitable for speaking skills but effective for writing skills only. This opinion is in line with the results in Shohamy, InbarLourie and Poehner's (2008) study whereby $85.8 \%$ of the participants voted for writing skills as a focus of portfolio assessment while just $46.2 \%$ agreed that portfolios could also be used for speaking skills.

In addition to some relative parallels above, there are some differences. While interviews in the current research obtained the first rank, they were rated at a very low place by the participants in Kim's (2003) and Munoz et al's (2003) studies. Furthermore, question and answer was used most frequently in Kim's (2003) and presentation in Munoz et al's (2003), but these two types were at the middle rank (5-6/11) in the present study. Finally, in Grada's (2014) study, along with self-assessment, peer-assessment was also rated as an inappropriate tool of speaking assessment in a secondary school context whereas peer-assessment received strong agreement from the teachers in this study.

The interviewed teachers provided information that help explain further why 
portfolios and self-assessment were least chosen as in-class speaking assessment task types although the mean scores of these two task types were still in the range of the medium level.

Concerning portfolios as an assessment task type for speaking skills, one of the main reasons for its least being selected is the effectiveness of portfolios on other skills, for example, writing, listening or reading skills, rather than speaking skill. One of the interview participants stated: "I don't think it's a good idea. Portfolio is more suitable for listening and writing". Another added: "Portfolio sounds suitable for reading and writing skills rather than speaking". In addition to the tendency to refuse using portfolios in speaking assessment, the participants were worried about some issues such as limited time, overloaded curriculum, etc. Hence, they were wondering if portfolios really helped in classroom speaking assessment. While some teachers admitted that they know nothing about portfolios, one teacher confirmed that it is practical only if teachers know how portfolios should be used efficiently and how students make significant improvements on their speaking skill. It can be therefore concluded that the teacher participants in this study lacked knowledge of using portfolios in general and speaking portfolios (oral portfolios) in particular.

Whether the interviewed teachers in this study have proper perception of oral portfolios or not will be clarified here in the light of the literature. Portfolios not only focus on the four macro skills of a learner as a whole, but can be developed to enhance a particular skill. According to O'Malley and Pierce (1996), oral portfolios are designed to empower learners' oral skills to communicate effectively. There are some common technology-based oral portfolios such as audio, visual and electronic portfolios. Students could use audio cassettes and place their recordings in portfolios or store their work and accomplishments through videotaping (Yoshida, 2001). Video records could be stored and shared among peers, which lends to a more visual and audio realism within the portfolios (Cole et al., 2000). Some examples of activities allowing video-record documentation such as roleplays, demonstrations, reports, discussions, and projects have been suggested by Johnson and Rose (1997). What is more, oral portfolios are proved to be effective in terms of selfreflection and self-monitoring in some studies (e.g., Bolliger \& Shepherd, 2010; Wang \& Chang, 2010; Castañeda \& RodríguezGonzález, 2011). In sum, it is obvious that portfolios can be effective and appropriate for speaking skills; therefore, the participants' view that portfolios are merely suitable for other skills is inappropriate.

With relation to self-assessment as an assessment task type for speaking skills, the data from the interview show that most of teachers agreed student self-assessment can be used in speaking assessment because it brings students many benefits such as making self-correction and self-improvement, being aware of their strengths and weaknesses, etc. In fact, self-assessment is beneficial to students in terms of different aspects. Oskarsson (1989) mentioned six advantages of using self-assessment in the language classroom: promotion of learning, raised level of awareness, improved goal-orientation, expansion of range of assessment, shared assessment burden, and beneficial post-course effects. Blue (1994) further identified the benefits of self-assessment such as encouraging more efforts, boosting self-confidence, and facilitating awareness of the distinction between competence and performance as well as self-consciousness of learning strengths and weaknesses. In addition, self-assessment is considered necessary for effective lifelong 
learning (Boud, 1995). Despite its numerous advantages, self-assessment received the second lowest mean of the task list. The interview data indicate teachers' doubts about implementing self-assessment. One of the interviewees, from her experience, explained that "students are not really serious in assessing themselves". Another teacher suggested that teachers need detailed checklists and every single assessment be explained clearly to the students. Other teachers also confirmed: "student selfassessment is not enough; student selfassessment, peer assessment and assessment from teachers should be combined flexibly in a language class". Teachers should therefore take these issues into consideration when making use of self-assessment for speaking skills. assessment and the teachers' doubts about whether and how self-assessment can be implemented in speaking assessment.

\subsection{Teachers'perception of the work involved in assessment implementation}

Because the work was separated into three stages: pre-, while- and post- which respectively means the work teachers prepare for assessment, the work teachers do while conducting assessment and the work teachers do after completing assessment activities, the findings and discussion also follow three parts of this division.

\subsubsection{Pre-stage}

The data about teachers' perceptions of the work involved in in-class speaking assessment application at the preparation stage were analyzed and summarized in Table 3.

Table 3. Teachers' perception of the work involved at the pre-stage of the assessment implementation

\begin{tabular}{|c|c|c|c|}
\hline No & Items & M & S.D \\
\hline 22 & Teachers should prepare assessment plan carefully. & 4.55 & 0.71 \\
\hline 23 & $\begin{array}{c}\text { Teachers should choose assessment tasks which help to get information about } \\
\text { students' ability to use language effectively. }\end{array}$ & 4.50 & 0.59 \\
\hline 24 & Teachers should inform students about assessment beforehand. & 4.00 & 0.94 \\
\hline 25 & $\begin{array}{c}\text { Teachers should consider assessment criteria to be used when they } \\
\text { design language assessment plan. }\end{array}$ & 4.43 & 0.70 \\
\hline 26 & $\begin{array}{c}\text { Teachers should connect the selection of assessment criteria } \\
\text { with the aim of language assessment. }\end{array}$ & 4.43 & 0.55 \\
\hline 27 & $\begin{array}{c}\text { Teachers should inform assessment criteria to students before conducting } \\
\text { assessment. }\end{array}$ & 4.10 & 0.69 \\
\hline \multicolumn{2}{c}{ Total Mean } & $\mathbf{4 . 3 3}$ & \\
\hline
\end{tabular}

In general, the different task types of inclass speaking assessment were perceived positively by the EFL teachers in the current study. The interactive tasks such as interviews, role-plays were much more preferable to the others in the list whereas speaking portfolios and self-assessment were not much supported owing to the teachers' limited knowledge about portfolios as a type of English speaking
In general, teachers' perceptions of the work involved in in-class speaking assessment application process at the pre-stage are highly appropriate. The participants' responses to all 6 items were fairly homogeneous, in the mean range from 4.00 to 4.55 . Specifically, the teachers thought that they should take into account not only the careful preparation for assessment plans but also the selection 
of suitable tasks for effective assessment. In line with this finding, the participants in Grada's (2014) study also showed agreement and strong agreement (96.1\%) with the use of assessment tasks which help to get information about students' ability of using language effectively.

Additionally, in order to have better speaking assessment, teachers assumed that they should be concerned about the issues such as the selection of relevant assessment criteria, the connection between the criteria and the assessment aims, as well as informing assessment criteria to the students beforehand. In particular, the findings on items 25 and 26 in relation to assessment criteria were also consistent with those in Grada's (2014) study whereby $94.7 \%$ and $93.4 \%$ of the participants showed agreement and strong agreement, respectively.

\subsubsection{While-stage}

This section analyses how high school English teachers perceive the work involved in in-class speaking assessment implementation at the while-stage. Table 4 below shows the means and standard deviations of the responses with reference to each item.
On the whole, the teachers showed positive perceptions of the work involved in assessment application process at the while-stage, which is indicated through the mean values in the range of high level. The highest mean score item (31) reveals that while assessing speaking, teachers should set speaking tasks at an appropriate level of difficulty. Table 4 also informs that teachers should do some other important jobs while assessing students, for example, taking notes carefully, explaining clearly to the students how to do assessment tasks, using many different assessment tasks and recording/ videotaping students' performances for more accurate assessment. Regarding the job of recording/videotaping students'performances, it does not get as very high mean $(\mathrm{M}=3.76)$ as the others. Nonetheless, as spoken language is transient, Heaton (1991) recommended that teachers should use a tape recorder to assist the assessment, where examiners are able to check back and forth when making assessment. In harmony with the findings of this section, a majority of the participants in Grada's (2014) study agreed and strongly agreed with two statements "teachers should use many different language assessment

Table 4. Teachers' perception of the work involved at the while-stage of the assessment implementation

\begin{tabular}{|c|c|c|c|}
\hline No & Items & Mean & S.D \\
\hline 28 & $\begin{array}{c}\text { Teachers should record or videotape students' performances for more } \\
\text { accurate assessment. }\end{array}$ & 3.74 & 0.99 \\
\hline 29 & Teachers should take notes carefully while assessing students. & 4.38 & 0.76 \\
\hline 30 & $\begin{array}{c}\text { Teachers should clearly explain to the students how to do } \\
\text { oral assessment tasks. }\end{array}$ & 4.24 & 0.79 \\
\hline 31 & Teachers should set speaking tasks at an appropriate level of difficulty. & 4.48 & 0.59 \\
\hline 32 & Teachers should assess the content of students' performance. & 4.10 & 0.66 \\
\hline 33 & Teachers should assess students' fluency. & 4.38 & 0.62 \\
\hline 34 & Teachers should assess students' pronunciation. & 4.29 & 0.55 \\
\hline 35 & Teachers should assess students' interaction. & 4.36 & 0.53 \\
\hline 36 & Teachers should assess students' grammar. & 3.62 & 0.94 \\
\hline 37 & Teachers should assess students' vocabulary. & 4.26 & 0.77 \\
\hline 38 & Teachers should make use of different language assessment tasks. & 4.19 & 0.83 \\
\hline \multicolumn{2}{r}{ Total Mean } & $\mathbf{4 . 1 8}$ & \\
\hline
\end{tabular}


tasks" (94.2\%) and "teachers should clearly explain to the students how to do language assessment tasks" (81.6\%).

Finally, the work teachers should do while assessing speaking is assessing students' performance based on certain criteria such as content, fluency, pronunciation, interaction, grammar and vocabulary. Out of 6 criteria, fluency (item 33) and interaction (item 35) received the highest mean scores, 4.38 and 4.36 respectively, whereas grammar was at a medium level with the lowest mean, 3.62. The order of the speaking assessment criteria in terms of the means from the highest to the lowest is illustrated in Figure 2. lowest range of the criteria list. The teachers underlined that students are considered being successful in speaking if they can get their message across. Moreover, to reduce the students' fear of making grammatical errors in speaking, teachers should not pay too much attention to students' grammar. The interviewed teachers also suggested that only repetitive and major grammar errors should be taken into consideration. These opinions are reasonable because Thornbury (2005) advised that grammatical accuracy is only one of several factors, therefore, when assessing speaking, teachers need to bear in mind that even native speakers produce non-grammatical

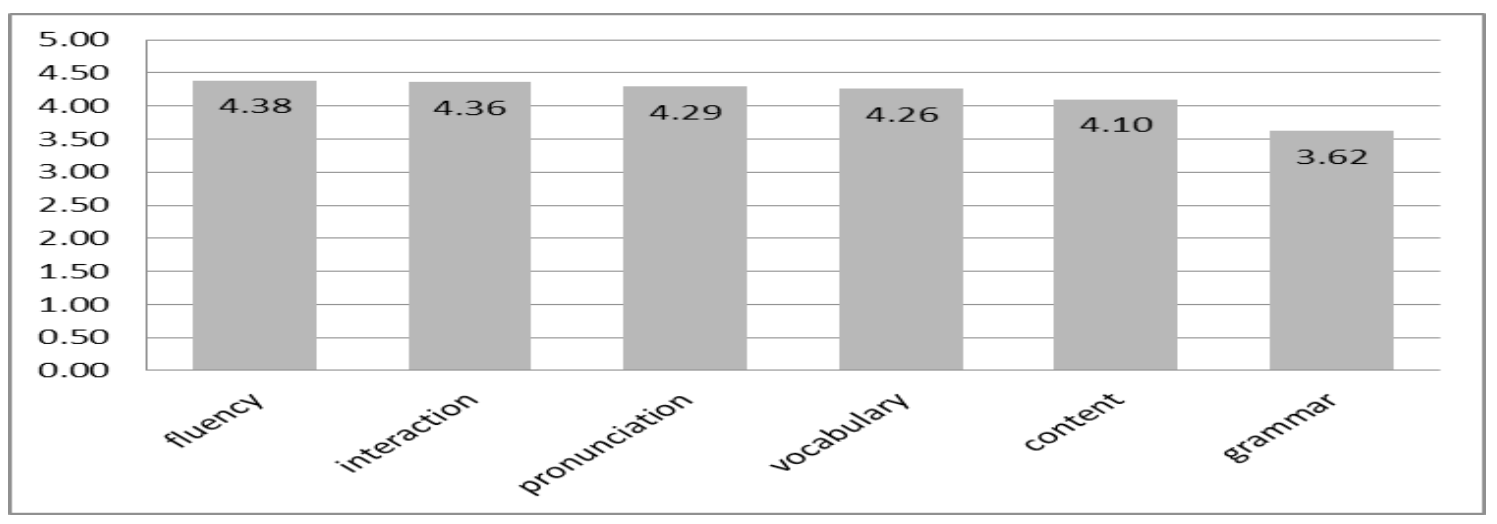

Figure 2. Criteria in speaking assessment

As can be seen from Figure 2, fluency, interaction, pronunciation, and vocabulary are in approximately equal positions, followed by content and grammar ranked as the lowest. This finding is out of line with Munoz et al's (2003) and Grada's (2014) studies in which grammar was firstly selected by teachers when assessing speaking. In addition, it is noticeable that the teachers' selection of the criterion interaction here is very consistent with their selection of assessment tasks involving high interaction level (e.g., role plays and interviews) as already discussed in section 4.2 .

In relation to grammar, the interview data proclaims some reasons why grammar is at the forms in fast, unmonitored speech. As a result, it would be unfair if teachers request that students achieve grammatical accuracy in all speaking situations. 
4.3.3. Post-stage

at the two ends of the medium range, 3.62 and 2.45 , respectively. Among the teachers'

Table 5. Teachers' perception of the work involved at the post-stage of the assessment implementation

\begin{tabular}{|c|c|c|c|}
\hline No & Items & Mean & S.D \\
\hline 39 & Teachers should give feedback to students immediately and timely. & 3.62 & 0.91 \\
\hline 40 & $\begin{array}{c}\text { Teachers' feedback should enable each student to identify his/her strengths } \\
\text { and weaknesses. }\end{array}$ & 4.43 & 0.55 \\
\hline 41 & $\begin{array}{c}\text { Detailed comments should be given rather than marks because students } \\
\text { benefit more from detailed comments. }\end{array}$ & 4.40 & 0.77 \\
\hline 42 & Teachers should give students both comments and marks. & 3.83 & 0.82 \\
\hline 43 & $\begin{array}{c}\text { Giving feedback to individual students' oral performance might affect the } \\
\text { teaching and learning process. }\end{array}$ & 3.83 & 1.01 \\
\hline 44 & $\begin{array}{c}\text { Giving frequent feedback on student performance might have a negative } \\
\text { impact on the relationship between students and teachers. }\end{array}$ & 2.45 & 1.33 \\
\hline & Total Mean & $\mathbf{3 . 7 6}$ & \\
\hline
\end{tabular}

As shown in Table 5, item 40 obtained the highest mean score (4.43), which indicates that the teachers placed important focus on feedback which helps students to identify their strengths and weaknesses. Accordingly, in responding to item 41 , the teachers emphasized meaningful comment feedback rather than marks $(\mathrm{M}=4.40)$. On the one hand, the teachers claimed that students can get more benefits from detailed comments than marks (item 41, M=4.40); on the other hand, they believed that both comments and marks should be given to students (item 42, $\mathrm{M}=3.83$ ). One more item entailing teachers' high level of perception is that giving feedback to individual students might have effects on the teaching and learning process (item 43, M=3.83). These findings were in high accordance with those of Fetene's (2008) study, in which pre-service teachers perceived the pedagogical functions of feedback at high level.

On the contrary to the 4 items at high level of perception as mentioned above, the issues raised in items 39 and 44 were perceived at medium level with the mean scores being responses to these two items, most teachers tended to disagree with the statement that the relationship between students and teachers might be negatively affected by teachers' frequent feedback. One interviewed teacher later emphasized that it was not the feedback but how the feedback was given that counts. If the teachers' feedback makes students feel comfortable and motivated, it will be effective, otherwise, the students might feel hurt. In the latter situation, that teachers' feedback might cause negative impacts on teachers and students' relationship. Another teacher added: "giving frequent feedback on student performance will be good if teachers know how to give objective, positive and constructive feedback. Even short compliments on students' work, their attempt to accomplish the task will make them feel happy and have motivation to learn. Without teachers' giving feedback, students might think that their teachers pay little attention to their performance".

\section{Conclusion and implications}

The results from both quantitative and qualitative data indicated that the teachers generally had positive perceptions towards 
in-class speaking assessment. Concerning the teachers' general understanding of speaking assessment, it was highly appropriate in terms of both the necessity and the purposes of speaking assessment. The teachers also emphasized the purposes of formative assessment over those of summative assessment. With regard to the teachers' perception of the task types of in-class speaking assessment, the interactive tasks such as interviews, role-plays were perceived as the most favorite ones. Nonetheless, the teachers had limited knowledge about portfolios as a task type for speaking assessment and they also needed more instructions on how to implement self-assessment in speaking assessment. Additionally, the teachers had quite appropriate perceptions of the work involved in the assessment implementation at three stages namely pre-stage, while-stage and post-stage, whereby the most highlighted perception is that grammar was considered as the least important criterion when assessing students' speaking performance.

Although the teachers had positive perceptions of in-class speaking assessment in general, they lacked knowledge about some task types of speaking assessment. The results of this study suggest that teachers need to be offered more theoretical and practical knowledge so that they can apply meaningful speaking assessment to their teaching. In addition, in-service teachers should be allowed and encouraged to participate in the professional development activities frequently such as seminars, workshops, conferences, and training courses. Pre-service teachers should also be equipped with sufficient knowledge about language testing and assessment.

Many issues relevant to assessing speaking skills have not been exploited yet in this study; therefore, further studies should be conducted. Since this study only focused on high school English teachers' perceptions of in-class speaking assessment, further research can explore the high school teachers' practice of in-class speaking assessment in order to see the similarities and differences between teachers' perceptions and practice. Future studies can also focus on lower-secondary school English teachers as research participants. Additionally, students' perceptions of in-class speaking assessment can be a potential area to be investigated.

\section{References}

Agasøster, S. (2015). A study of assessment practice of oral English at lower secondary schools in Norway. Unpublished MA thesis. University of Bergen, Norway.

Bingqing, F. (2009). Middle school English teachers perceptions of oracy and their practice of speaking assessment, Teaching English in China-CELEA Journal, 32(6), 27-39.

Blue, G. (1994). Self-assessment of foreign language skills: Does it work?. CLE Working Paper, 3, 1835 .

Bolliger, D. U., \& Shepherd, C. E. (2010). Student perceptions of e-portfolio integration in online courses. Distance Education, 31(3), 295-314.

Boud, D. (1995). Enhancing learning through selfassessment. London: Kogan Page.

Brown, H. D. (2004). Language assessment: Principles and classroom practices. New York: Pearson Education.

Castañeda, M., \& Rodríguez-González, E. (2011). L2 Speaking self-ability perceptions through multiple video speech drafts. Hispania, 94(3), 483-501.

Chang, C-W. (2006). Teachers' beliefs towards oral language assessment in Taiwan Collegiate EFL classrooms, 2006 International Conference on English Instruction and Assessment, Fooyin University.

Chuang, Y. Y. (2007). A study of college English teachers' preferences and perceptions of using the types of tasks for assessing Taiwanese EFL students' foreign language oral proficiency. Journal of Applied Foreign Languages, 8, 74-105.

Cole, D. J., Ryan, C. W., Kick, F., \& Mathies, B. K. (2000). Portfolios across the curriculum and beyond (2nd Ed.). California: USA.

Dörnyei, Z. (2003). Questionnaires in second language research: Construction, administration and processing. London: Lawrence Erlbaum Associates Inc.

Fetene, M. (2008). The challenges of implementing continuous oral assessment in EFL classes with 
reference to Debre-Birhan teachers' college. (MA thesis). Addis Ababa University, Addis Ababa, Ethiopia.

Grada, T. K. A. (2014). An investigation into Libyan EFL Novice Secondary School Teachers' current knowledge and practice of speaking assessment: A socio-cultural perspective (Doctoral dissertation). University of Exeter, United Kingdom.

Hattie, J., \&Timperley, H. (2007). The power of feedback. Review of Educational Research, 77(1), 81-112.

Heaton, J. B. (1991). Writing English language tests. USA, New York: Longman.

Johnson, N. J., \& Rose, L. M. (1997). Portfolios: Clarifying, constructing and enhancing. Pennsylvannia: Technomic Publishing Company.

Kim, H. (2003). The types of speaking assessment tasks used by Korean junior secondary school English teachers. Retrieved on August 10, 2016 from http:// www.asianefljournal.com/dec_03_gl_kr.php.

Lee, S. (2010). Current practice of classroom speaking assessment in secondary schools in South Korea (Master's thesis). The University of Queensland, Australia.

Luoma, S. (2004). Assessing speaking. Cambridge: Cambridge University Press.

Madsen, H. S. (1983). Techniques in testing. Oxford: Oxford University Press.

McMillan, J. H., \& Schumacher, S. (1993). Research in education: a conceptual introduction (3rd Ed.). New York. NY: Harper Collins.

MOET (2014). Dispatch No. 5333/BGDĐT-GDTrH: Implementing language testing and assessment in order to develop learners' English proficiency at secondary level from academic years 2014-2015. Hanoi.

Muñoz, A.P., Aristizábal, L. D., Orozco, F. C., Monsalve, S. G., Orozco, L. A. L., \& Urán, M. P. (2003). Assessing spoken language in EFL: Beliefs and practices. REVISTA Universidad EAFIT, 129, 64-73.

Nguyen, T. M. A. (2013). The impact of CEFR - B1 level on teaching and assessing speaking skill for non-English major students at Hue University's College of education (HUCE). Unpublished MA thesis. Hue University of Foreign Languages, Hue, Vietnam.

O'Malley, M., Pierce, L. V. (1996). Authentic assessment for English language learners: Practical approaches for teachers. USA: Addison- Wesley.

Oskarsson, M. (1989). Self-assessment of language proficiency: Rationale and applications. Language Testing, 6(1), 1-13.

Pham, T. H. N., \& Tran, T. T. S. (2014). Primary EFL teachers' perceptions of assessing young language learners. Conference Proceedings on "English language testing and assessment for school-age learners".

Shohamy, E., Inbar-Lourie, O., \& Poehner, M. (2008). Investigating assessment perceptions and practices in the advanced foreign language classroom (Report No. 1108). University Park, PA: Center for Advanced Language Proficiency Education and Research

Taylor, L. (2006). The changing landscape of English: implications for language assessment. ELT Journal, 60(1), 51-60.

Thornbury, S. (2005). How to teach speaking. Harlow, England: Longman.

To, T. T. H. (2010). Pedagogical base of foreign language testing and assessment at secondary schools in Vietnam. VNU Journal of Foreign Studies, 26(4), 262-278.

Tran, Q. B. (2010). Practical constraints in EFL Vietnamese classrooms affecting speaking assessment: A case study in Nam Dinh UpperSecondary schools. Unpublished MA thesis, Vietnam National University, Hanoi, Vietnam.

Tran, T. T. N., \& Nguyen, H. H. T. (2017). An investigation into the difficulties in implementing in-class English speaking and the required resources for its effective practice. 3rd National Conference on Interdisciplinary Research on Language and Language Teaching, Hue University of Foreign Languages.

Truong, T. N. (2010). The reality of assessing speaking skill of high school students at Nguyen Tat Thanh Gifted High School and recommendations. Unpublished MA Thesis, Vietnam National University, Hanoi, Vietnam.

Wang, L. J., \& Chang, H. F. (2010). Applying innovation method to assess English speaking performance on communication apprehension. Belt Journal, 1(2), 147-158. Retrieved from http:// revistaseletronicas.pucrs.br/ojs/index.php/belt/ article/viewFile/8218/64

Waugh, D., \& Jolliffe, W. (2008). English 3 - 11: A guide for teachers. Routledge: New York.

Winke, P., Gass, S., \& Myford, C. (2011). The relationship between raters' prior language study and the evaluation of foreign language speech samples (TOEFL iBT Research Report TOEFL iBT160). Princeton, NJ: Educational Testing Service.

Yoshida, Y. (2001). Authentic progress assessment of oral language: Oral portfolios. Retrieved November 15th, 2017, from http://eric.ed.gov/ PDFS/ED453674.pdf. 


\title{
NGHIÊN CỨU NHậN THỨC CỦA GIÁO VIÊN VỀ VIỆC ĐÁNH GIÁ KĨ NĂNG NÓI TIẾNG ANH TRONG LỚP HỌC
}

\author{
Nguyễn Hồ Hoàng Thủy ${ }^{1}$, Trần Thị Thanh $\mathrm{Nga}^{2}$ \\ ${ }^{I}$ Truò̀ng Đại học Ngoại ngũu, Đại học Huế, 57 Nguyễn Khoa Chiêm, An Cưu, Huế, Việt Nam
}

${ }^{2}$ Truờng THPT Huớng Hóa, Huớng Hóa, Quảng Trị, Việt Nam

Tóm tắt: Nghiên cứu này được thực hiện nhằm khám phá nhận thức của giáo viên về việc đánh giá kĩ năng nói tiếng Anh trong lớp học ở các khía cạnh sau: hiểu biết chung của giáo viên về đánh giá kĩ năng nói, nhận thức của giáo viên về một số hoạt động được sử dụng và về các công việc của họ liên quan đến đánh giá kĩ năng nói tiếng Anh trong lớp học ở một số trường THPT tại Quảng Trị. Dữ liệu được thu thập từ 42 phiếu điều tra và 5 cuộc phỏng vấn với các giáo viên tiếng Anh tại nhiều trường THPT khác nhau tại Quảng Trị. Kết quả nghiên cứu cho thấy nhận thức của giáo viên về việc đánh giá kĩ năng nói tiếng Anh trong lớp học nhìn chung khá phù hợp; tuy nhiên, giáo viên vẫn còn thiếu kiến thức về việc sử dụng bộ tài liệu học tập (portfolios) như là một hoạt động có thể dùng để đánh giá kỹ năng nói và các thầy cô cũng cần có thêm hướng dẫn để áp dụng hình thức học sinh tự đánh giá kĩ năng nói của bản thân.

Từ khóa: nhận thức của giáo viên, đánh giá kĩ năng nói, dạng bài tập đánh giá 